
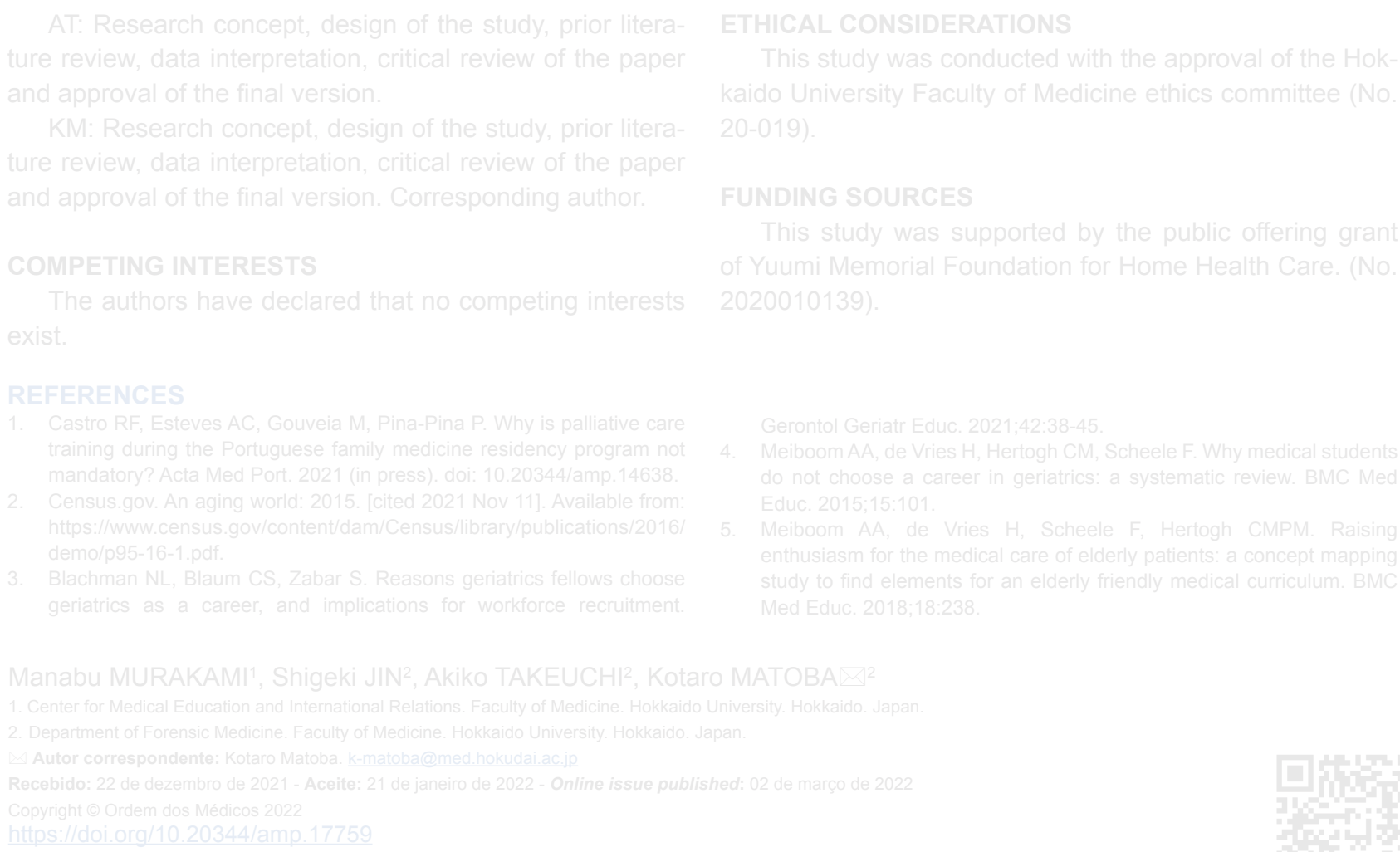

\section{Reflections on the Relevance of Culture in Psychiatry} and Medicine

\section{Reflexões sobre a Relevância da Cultura em Psiquiatria e na Medicina}

Keywords: Anthropology; Ethnopsychology/classification; Psychiatry

Palavras-chave: Antropologia; Etnopsicologia/classificação; Psiquiatria

Dear Editor,

A recent article raised relevant questions regarding the specific healthcare needs of vulnerable populations of refugees and migrants in Europe and prompted the authors to briefly reflect on the role of culture in medicine. ${ }^{1}$

Culture is an essential dimension in medicine. Psychiatry is paradigmatic with the exotic nature of certain behaviours in different cultures sparking the interest of early colonial psychiatrists and anthropologists. ${ }^{2}$ Despite the recognition of the limitations of the early descriptions, many traces of that aesthetic wonder have persisted throughout the years transpiring into modern psychiatric nosology and medical practice. ${ }^{2}$ Over the years, thinkers such as Frantz Fanon voiced their critical view of the colonial origins of psychopathology. ${ }^{3,4}$ Disease classification systems (e.g. World Health Organization's International Classification of Diseases) were essential to bring validity and reliability to previously erratic diagnoses. However, some authors question the universality of diagnostic categories, highlighting the importance of recognizing the individual ways in which we express suffering through our personal narratives and the risk of medicalization of behaviours. ${ }^{4}$ Cultural syndromes were an intrinsically problematic construct in the sense that they were not in fact culture-bound but rather culture-related; and not true syndromes according to the medical model. These included local explanations or causal attributions of certain behaviours, folk diagnostic labels, different idioms of expression of distress or metaphors. ${ }^{2}$ If one wants to develop more robust diagnostic manuals our positivistic third-person approach has to be complemented with phenomenological subjective and intersubjective approaches to inform our research and the way we conceptualize symptoms. Exploration of the self and the basic structures of experience as well as the construction of shared narratives and interpretations allows a more comprehensive understanding of the illness experience of our patients. ${ }^{5}$ Every human experience, including illness, is necessarily embedded in social and cultural processes. These processes transform even the most essential biological and physiological disturbances' translation into symptoms and behaviors through the lens of particular cultural codes. ${ }^{2}$ The interactions between our own subjectivity and intersubjectivity with culture are essential for a proper understanding of everyday clinical practice.

We hope our work prompts clinicians and researchers to adopt an approach that integrates different frameworks (from genetics to large-scale networks, narrative structures 
and social networks) and using different but complementary methods (epidemiology, phenomenology, neurophysiology, neuroimaging, etc.). Otherwise, we risk building knowledge upon increasingly frail foundations, thus hindering the understanding and ultimately the care provided to patients.

\section{AUTHORS CONTRIBUTION}

TT: Concept of the work, draft of the manuscript, critical review.

SVBG: Critical review of the paper.

\section{PROTECTION OF HUMANS AND ANIMALS}

The authors declare that the procedures were followed according to the regulations established by the Clinical Research and Ethics Committee and to the Helsinki Declaration of the World Medical Association updated in 2013.

\section{REFERENCES}

1. Mota P, Neto A. Uso de substâncias em populações de refugiados: propostas de abordagem a uma população vulnerável. Acta Med Port. 2021;34 (In press). doi: 10.20344/amp.16624.

2. Kirmayer LJ. Cultural psychiatry in historical perspective. In: Bhugra D, Bhui K, editors. Textbook of cultural psychiatry. 2nd ed. Cambridge: Cambridge University Press; 2018. p.1-17.

\section{DATA CONFIDENTIALITY}

The authors declare having followed the protocols in use at their working center regarding patients' data publication.

\section{COMPETING INTERESTS}

The authors have declared that no competing interests exist.

\section{FUNDING SOURCES}

This research received no specific grant from any funding agency in the public, commercial, or not-for-profit sectors.

3. Butts HF. Frantz Fanon's contribution to psychiatry: the psychology of racism and colonialism. J Natl Med Assoc. 1979;71:1015-8.

4. Kleinman $A$. The illness narratives: suffering, healing, and the human condition. New York: Basic Books; 1988.

5. Fuchs T. Subjectivity and intersubjectivity in psychiatric diagnosis. Psychopathology. 2010;43:268-74.

\section{Tomás TEODORO $\triangle^{1,2,3}$, Sara VILAS BOAS GARCIA ${ }^{1,4}$}

1. Early Intervention \& Transition Unit (Clínica 1 - Unidade Partilhada). Department of Psychiatry. Centro Hospitalar Psiquiátrico de Lisboa. Lisbon. Portugal.

2. Adult ADHD \& Neurodevelopmental Disorders Outpatient Clinic. Department of Psychiatry. Centro Hospitalar Psiquiátrico de Lisboa. Lisbon. Portugal.

3. CHRC - Comprehensive Health Research Centre. NOVA Medical School|Faculdade de Ciências Médicas. Universidade NOVA de Lisboa. Lisbon. Portugal.

4. Young Adult (Sub25) Outpatient Clinic. Department of Psychiatry. Centro Hospitalar Psiquiátrico de Lisboa. Lisbon. Portugal.

$\triangle$ Autor correspondente: Tomás Teodoro. tomasteodoro@chpl.min-saude.pt

Recebido: 22 de dezembro de 2021 - Aceite: 26 de janeiro de 2022 - Online issue published: 02 de março de 2022

Copyright (C) Ordem dos Médicos 2022

https://doi.org/10.20344/amp.17762 